\title{
ENTRE AFETOS: reflexões a partir de uma experiência de aquilombamento teatral universitário
}

BETWEEN AFFECTIONS: reflections on an experience of
Quilombo university theatre

Jéssica Sampaio da Silva *

\section{Resumo}

Por meio da noção de aquilombamento teatral universitário, este artigo reflete sobre o processo de investigação do espetáculo Interiores do Coletivo Teatral Fraude Pura, e sobre as memórias afetivas que percorrem o corpo da artista que vivência e testemunha toda a ação. Ao afirmar-se enquanto corpo negro, o artista universitário baseia-se em construções contra-hegemônicas de ser e estar no mundo. Tais construções são motivadoras para gerar um olhar particular na criação artística universitária.

Palavras-chave: Processo de Encenação; Aquilombamento Teatral Universitário; CorpoTestemunha; Teatro Negro Universitário.

\begin{abstract}
Through the notion of Quilombo university theatre, this article reflects on the process of investigation of the show Interiors of the Theatre Collective Fraude Pura, and on the affective memories that run through the body of the artist who experiences and witnesses all the action. By asserting himself as a black body, the university artist relies on counter-hegemonic constructions of being and being in the world. Such constructions are incentives to generate a particular look at university artistic creation.

Keywords: Staging Process; Quilombo University Theatre; Body Witness; University Black Theater.

[...] O laçar de mãos não pode ser algema e sim acertada tática, necessário esquema.

É tempo de formar novos quilombos, em qualquer lugar que estejamos $[\ldots]$.
\end{abstract}

(EVARISTO, 2020).

\section{Apresentação}

Enquanto concepção política, o quilombo está ressignificado, tem novas estruturas e lida com outras forças. A partir dessa perspectiva, surgiu em 2017, o Coletivo Fraude Pura, integrado por estudantes da Escola de Teatro da Universidade Federal Bahia

\footnotetext{
* Graduada em Gestão Ambiental pela UNIJORGE, licencianda em Teatro pela UFBA/Brasil. Atriz, pesquisadora e agitadora cultural dos coletivos teatrais "E" ao Quadrado e Fraude Pura. E-mail: jessicasampaio92@hotmail.com.93
} 
(UFBA), com objetivo de apostar em encenações que contassem as suas histórias, sob uma abordagem antirracista.

O primeiro contato entre esses estudantes (que despertou laços afetivos) aconteceu durante a prova de habilidades específicas, última etapa de seleção do vestibular. De concorrentes a colegas de turma, a união se fortaleceu na militância universitária, quando passaram a integrar algumas intervenções cênicas, o que resultou (organicamente) na formação de um coletivo de teatro universitário.

O nome Coletivo Fraude Pura é uma brincadeira em alusão à aprovação desses estudantes (todos negros). Uma "subversão" do processo seletivo do vestibular da Escola de Teatro da UFBA, que tradicionalmente aprovava candidatos majoritariamente brancos. A partir disso, o Coletivo via a potência de sua união como uma forma de questionar as narrativas a respeito do lugar que corpos negros ocupam no sistema de arte, construindo um discurso contra-hegemônico, ao criar um posicionamento debatedor.

Em sua formação inicial, o Coletivo Fraude Pura integrou Aila Monteiro, Alexandre Militão, Ângela Oliver, Ayran Bufálo, Fabiola Sena, Iago Gonçalves, Jéssica Sampaio, Juliana Bispo, Lorena Bastos, Manu Moraes, Matheus Menezes, Matheus Zumborí, Rafaela Tuxá. Posteriormente, juntaram-se ao grupo Jéssica Carolina e Silara Aguiar. Todas e todos são oriundos de municípios do interior da Bahia, ou da periferia de Salvador (o qual chamaremos de "interior de Salvador"). Essa referência geopolítica social, comumente usada por nós dentro do Coletivo, foi a inspiração para a investigação cênica, que resultou na encenação do espetáculo Interiores.

O espetáculo transita entre a memória dos atores, revelando as relações com a geografia e as saudades. Carregado de ancestralidade, traz à tona conhecimentos que se confrontam com a realidade urbana. O espetáculo é como um trem que vai ao encontro do tempo, no qual os passageiros (agentes dessa experiência) percorrem cenas sobre diferentes temáticas e diferentes cenários interioranos: o cenário rural, o urbano, a poesia e a noção de família.

Observando o processo de formação do Coletivo Fraude Pura e a construção do espetáculo Interiores, percebi diversos atravessamentos e sensibilidades baseados em relações afetivas, que eram fundamentais para o fenômeno que passei a tratar por aquilombamento artístico universitário. Ser integrante desse coletivo, tornou-me capaz de 
reconhecer o lugar de fala dos sujeitos, identificando suas vozes e silêncios sociais. Partilhando meu conhecimento como artista, adquiri uma perspectiva privilegiada a esse respeito, entendendo minhas reflexões como corpo-testemunha. ${ }^{1}$

Dessa forma, é possível reconhecer o lugar de fala dos sujeitos, identificando suas vozes sociais (e silêncios) pelo compartilhamento do meu conhecimento como artista.

\begin{abstract}
Ninguém se forma no vazio. Formar-se supõe troca, experiência, interações sociais, aprendizagens, um sem-fim de relações. Ter acesso ao modo como cada pessoa se forma é ter em conta a singularidade de sua história e, sobretudo, o modo singular como age, reage e interage com os seus contextos. Um percurso de vida é assim um percurso de formação, no sentido em que é um processo de formação. (MOITA, 1995, p. 115 apud MACHADO, 2013, p. 28).
\end{abstract}

Interiores não se resume a um espetáculo teatral. Trata-se de um laboratório poético de memórias dos artistas, que costura cosmovisão e seus olhares em um contexto acadêmico, reunindo diferentes perspectivas que se comunicam como um corpo vivo e energético. É uma criação poética do Coletivo Fraude Pura a partir de histórias de vida, partilhas de narrativas sobre culturas e memórias pessoais.

Por ser um coletivo universitário afrocentrado (que se engajou na atuação política e estética), pode-se verificar seu êxito como fortalecimento das ideias e concepções teatrais, em diálogo com o debate étnico-racial. Este artigo apresenta algumas reflexões defendidas originalmente em uma monografia apresentada em 2020, como trabalho de conclusão do curso de Licenciatura em Teatro da UFBA (SILVA, 2020).

\title{
Lugar de fala e corpo-testemunha a partir de uma experiência no teatro negro universitário
}

Enquanto corpo-testemunha nessa encruzilhada de narrativas, que se forma como um laboratório poético de um teatro negro universitário, percebo a importância de acumular vivências e poder sistematizá-las. Situo, então, meu "lugar de fala" (RIBEIRO, 2019) como artista negra, aprendiz e educadora, capaz de transitar e promover o diálogo

\footnotetext{
${ }^{1}$ Segundo Stênio Soares (2020), o artista, enquanto sujeito social, não está isolado do mundo, ele carrega consigo coisas oferecidas pelo mundo, e as coisas que ele constrói, deixa no mundo. Nesse sentido, ele aborda o conceito de corpo-testemunha, a partir das impressões coletivas sob um ponto de vista específico da experiência vivida pelo sujeito em si.
} 
entre diferentes áreas de conhecimento. Os caminhos de saberes, nos quais me encontro, fazem com que repense os meus modos de ser e estar no mundo e o compartilhamento dos meus conhecimentos por meio de uma arte e de uma "pedagogia engajada" (HOOKS, 2013). Compreendendo, dessa forma, que minha experiência de vida se entrelaça em diversos modos de coexistência numa perspectiva plural.

Como sujeita social, percebo que o chamado "teatro negro" é constituído por estas experiências, afetividades e conhecimentos.

Seguindo o entendimento de Leda Maria Martins (1987, p. 228), “a expressão Teatro Negro é aqui utilizada para identificar um certo tipo de peças que têm o negro como macro signo cênico e cujos autores tentam problematizar a sua presença em cena como vetor de tensões". Antes de falar sobre a experiência de observação no coletivo artístico, faz-se necessário esboçar os atravessamentos subjetivos que interferem na forma como vejo o mundo e o descrevo.

Gramaticalmente, a palavra sujeito é do gênero masculino, mas pode ser aplicada a ambos os gêneros. Assim como "bell hooks" em sua crítica feminista (feita ao perceber a marcação de gênero que seu texto sofreria na tradução do inglês para o português), optei por referir-me como "sujeita".

Sou uma mulher negra e suburbana, e reconheço que pude agarrar algumas oportunidades, que na maioria das vezes não nos são ofertadas. Entendo, portanto, essas oportunidades como "subprivilégios". Afinal, posso atestar as dificuldades para conseguir alcançar alguns objetivos e seguir alguns percursos. Para mim, as oportunidades soam mais como uma reparação social e histórica de tudo que foi negado aos meus antepassados. Posso, dessa forma, aproveitá-las para auxiliar outros a irem além. Sabendo, como recorda Akotirene, que "pretas e pretos são pessoas pretas em qualquer lugar do mundo" (AKOTIRENE, 2019, p. 37).

Nesse processo de imersão, junto ao Coletivo Fraude Pura, teço memórias a partir do meu corpo-testemunha. Essas memórias refletem o encruzilhar de suas histórias e serviram de testemunhas para uma novo pensar, refletido nos processos de artivismo negro e de um teatro negro. 


\begin{abstract}
Ao depor sobre o fenômeno vivido, a linguagem se manifesta como um testemunho do próprio artista negro como um sujeito social, e sua linguagem é um comprometimento do seu corpo. Por isso, entendemos que essas criações se apresentam como depoimentos do corpo-testemunha, e por tanto, elas são formas de conhecimento e formas de empoderamento dos artistas negros, que comprometem e empregam, a partir do seu próprio corpo, as impressões coletivas sob um ponto de vista da experiência vivida por si. (SOARES, 2020, p.13)
\end{abstract}

De acordo com Soares (2020), o conceito do corpo-testemunha se aproxima e dialoga com o debate do feminismo negro de Patrícia Collins, como forma de conhecimento do ethos na sociedade negra, sob o ponto de vista da própria pessoa negra que vive, percebe, e sofre na pele o fenômeno que observa. Para o autor, as ideias passam a ser estruturadas nos discursos poéticos a partir de uma tomada de consciência dos artistas negros brasileiros que reafirmam uma luta atravessada, percebida, vivida e experimentada a partir do corpo-testemunha.

Enquanto corpo-testemunha, carrego as memórias que atravessam meu processo artístico-pedagógico: como aprendiz, inicialmente, em espaços informais de ensino, e depois em espaços formais; e, como artista-educadora, em processos de ensinoaprendizagem. Neste lugar de encruzilhada, situo poéticas e estéticas negras voltadas para um engajamento social (tanto de grupos, quanto de indivíduos) que são capazes de subverter um sistema artístico marcado pelo racismo estrutural (ALMEIDA, 2018).

\title{
Coletivo Fraude Pura: um aquilombamento entre afetos
}

\section{Se a mente é afetada uma vez simultaneamente por duas afecções, tão logo seja afetada por uma, será pela outra afetada.}

(SPINOZA, 2014, p. 211).

A palavra "quilombo" nos remete aos refúgios de escravos africanos e afrodescendentes. Cabe ponderar que a definição de quilombo é passível de contradições e diferenças. A historiografia já demonstrou que, enquanto espaço de poder, o quilombo também representava um lugar de disputas. Ocorre que o ideal do quilombo, como lugar de reunião de forças, inspirou o movimento brasileiro do quilombismo e esta, por sua vez, é uma abordagem interessante para manifestações desse fenômeno no interior dos movimentos negros. O Coletivo Fraude Pura é formado por pessoas diferentes, com 
pensamentos diferentes, mas que também têm muitos objetivos em comum em torno de questões étnico-raciais, o respeito, o cuidado e seus afetos.

Abdias Nascimento (2019) abordou sobre o quilombismo em relação à vivência da cultura e de práxis da coletividade negra, seus conceitos e definições enriquecem e potencializam a chamada luta antirracista. Em uma definição de quilombo, ele afirma que:

[...] precisamos e devemos codificar nossa experiência por nós mesmos, sistematizá-la, interpretá-la e tirar desse ato todas as lições teóricas e práticas conforme a perspectiva exclusiva dos interesses da população negra e de sua respectiva visão do futuro. (NASCIMENTO, 2019, p. 289)

Como atender às necessidades de pessoas negras em uma comunidade como o quilombo, sendo ele também um espaço de disputas? Nascimento (2019) afirma que: a "significação do quilombo" quer dizer reunião fraterna livre, solidariedade, convivência, comunhão existencial. Todavia, a partir da observação da formação de um coletivo de teatro universitário, verifico que, para tal, a ideia de quilombo tem que estar vinculada à ideia de afetividade. Pois, devido às diferenças individuais e de subjetividades, por mais que tenhamos pautas políticas em comum na luta antirracista, sempre existem fatores que individualizam as necessidades de cada um.

Ao observar a manifestação política contemporânea do quilombo, como agrupamento de militância negra por afetos, congrego com Spinoza (2014) que entende os afetos por "aquelas [afecções] do corpo pelas quais a potência de agir desse corpo aumenta ou diminui, é favorecida ou coagida, e, ao mesmo tempo, as ideias dessas afecções [...] a entendo então por uma ação; as demais [entendo] como paixão." (SPINOZA, 2014, p. 197).

Nesse sentido, ao aproximar o aspecto do quilombismo definido por Nascimento (2019), com as proposições sobre afecções (tradução corresponde a afetos) de Spinoza (2014), compreendo que os laços que fortalecem o quilombismo, no contexto das artes cênicas, estão relacionados aos afetos enquanto paixão. Isso quer dizer que eles trazem consigo traços possíveis de semelhanças ou diferenças expostas por afetos menores. Pois, mesmo estando em uma organização coletiva, disputas por reconhecimento de si e do outro sejam possíveis. 
Em um aquilombamento teatral universitário, como o proposto pelo Coletivo Fraude Pura, pode se identificar as diferenças específicas de cada sujeito, reconhecendo as histórias individuais e se perguntando: Quem sou eu nesse espaço? Que lugar é esse? Como me relaciono com o outro?

Percebe-se que o processo de investigação do espetáculo Interiores, nas suas duas versões, traz pautas antirracistas para a cena teatral, com memórias reformuladas a partir de afetos e de um cuidado sensível entre os integrantes. No processo de reconhecimento de minhas histórias nas dos outros e dessa abertura de possibilidades de ouvir nossas narrativas, verificamos que algumas se entrecruzam, especialmente no que se refere à memória de uma educação matriarcal. Esse último ganha um contorno potente quando questionamos como essa memória de pessoas negras pode interferir no modo de se pensar a educação dentro do espaço universitário (cujo discurso hegemônico reproduz um pensamento tantas vezes insensível e eurocêntrico).

Esse poder feminino, presente nas memórias de cada integrante do coletivo, fez parte da construção desse aquilombamento teatral universitário. Ao perguntar quem sou dentro desse espaço (universitário), o porquê de estar nele - e no aquilombamento teatral - atravesso questões identitárias, referencio e fortaleço raízes ancestrais como forma de afetar o espaço acadêmico munida de nossas narrativas de vida, nutrindo-as de conhecimentos e saberes outros.

Das mesmas maneiras que somos afetados positivamente dentro do Coletivo Fraude Pura, também somos afetados negativamente. Somos um grupo de pessoas com histórias parecidas: negras (os), periféricas e/ou do interior, politicamente posicionados, mas com personalidades diferentes. Em alguns momentos, ocorrem estranhezas por estarmos num espaço de disputa, por causa desse contexto de pensamento hegemônico e eurocêntrico. Levando isso em consideração, Spinoza (2014, p. 248) traz outra pontuação: "uma afecção qualquer de um indivíduo difere da afecção de um outro, tanto quanto a essência de um difere da essência de outro."

Contudo, na construção de pontos em comum, esses afetos, que diferem um do outro na essência, acabam não se sobressaindo nos objetivos de ser, de fato, um quilombo. Ou seja, uma família dentro e fora da universidade, sendo ponto de apoio artístico. Essa mesma construção potencializa as qualidades uns dos outros. 
O aquilombamento teatral universitário, entre outros aspectos, tem por objetivo tanto apoiar a permanência e projetos artísticos dos estudantes no espaço acadêmico quanto contribuir com produções artísticos negrorreferenciadas (que possam intervir no repertório cultural e estético). Como observadora privilegiada do Coletivo Fraude Pura, pude perceber a importância desse aquilombamento para o desenvolvimento de artistas negros em formação. Desenvolvimento que é baseado tanto pelos laços afetivos quanto pela luta de existir e reexistir. Essas potências poéticas que narram suas próprias histórias e, com isso, fortalecem uma identidade cultural enquanto artistas.

\section{Interiores: notas a partir de uma criação poética de um aquilombamento teatral universitário}

A afirmação de ser um aquilombamento teatral universitário traz consigo toda uma história de manutenção e luta por permanência estudantil nesse espaço acadêmico. A partir do movimento de luta e aquilombamento desses estudantes universitários, foram criadas cenas nutridas pelas narrativas sobre esse interior do Estado, coisa que parece tão distante, e que tem algo de mítico. O processo que o Coletivo Fraude Pura experimentou na Escola de Teatro da UFBA, as dificuldades, os medos e anseios, momentos de alegria, confraternização dos seus integrantes; tudo passou a ser material de pesquisa, somado às memórias que antecedem o contexto universitário, que se referem ao trânsito migratório do interior do Estado da Bahia e das periferias de Salvador para estudar na UFBA.

Para Patrice Pavis (2011), a análise do espetáculo é uma tarefa que ultrapassa a competência de uma única pessoa. É preciso que ela leve em consideração a complexidade e a multiplicidade dos tipos de espetáculo, considerando as diversidades dos espetáculos contemporâneos.

O processo de encenação do espetáculo Interiores foi orientado pelo diretor Thiago Romero. A partir da minha experiência como observadora participante, inspirada na escritura de um corpo-testemunha, tecerei algumas considerações com o intuito de entender como essa produção repercutiu estratégias de um aquilombamento teatral universitário.

Antes, convém apontar que o espetáculo ocorreu de maneira embrionária em uma disciplina acadêmica intitulada "Processos de Encenação", quando trabalhamos estímulos 
e jogos teatrais para a construção da cena. Nessa etapa, cada integrante dirigiu uma cena. Fizemos uma bricolagem a partir das memórias e documentações reunidas e do método do teatro documentário. Fizemos a dramaturgia da cena, a produção, a organização dos ensaios e a encenação, tanto por ser resultado da disciplina, como pelo fato de ser a primeira experimentação poética que reunia a maioria dos integrantes do coletivo.

A cena de convite aos espectadores dava o tom que intuíamos. Um grande cortejo percorreu os pavilhões de aulas da UFBA, vendendo alguns quitutes, embalado pelas músicas cantadas pela Véia Duí, (avó de um dos integrantes do coletivo, Iago Gonçalves). Era um convite para um samba de roda, patrimônio cultural imaterial do recôncavo baiano, que invadia o pavilhão de aulas em direção à Sala Preta — sala-laboratório de cenas acadêmicas — onde acontecia a encenação das histórias.

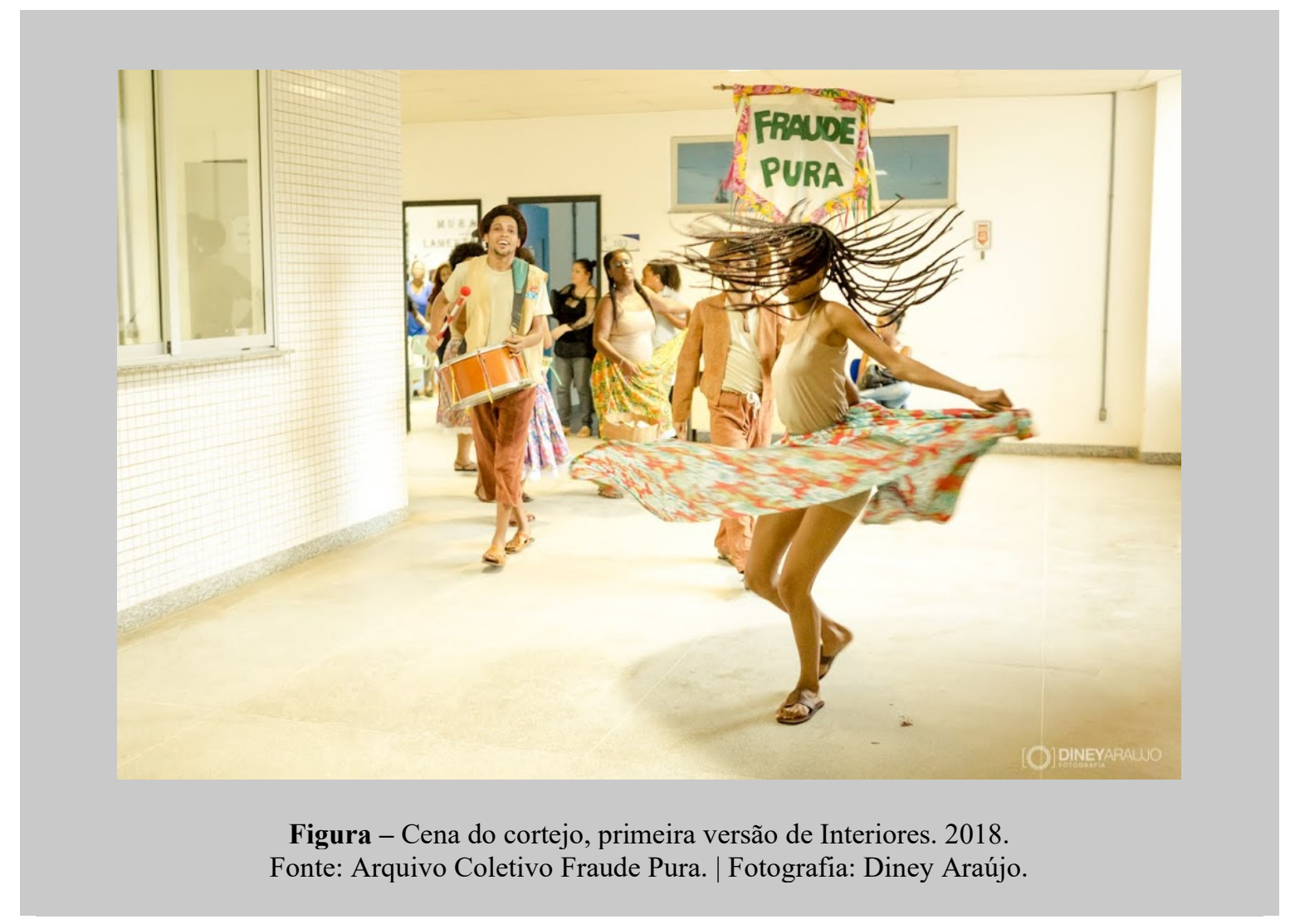

A cena resultante da disciplina abriu espaços para reafirmamos o Coletivo, e redirecionarmos o espetáculo Interiores a partir de outro ponto de vista. A segunda versão parte desse primeiro experimento cênico e da inscrição em um edital de fomento às 
produções artísticas universitárias, o PIBeXa. Após, a premiação do edital, convidamos Thiago Romero para conduzir as cenas e o processo dos ensaios em si. Seu trabalho fora nossa referência de pesquisa em teatro documentário para a realização do experimento da disciplina.

Sua experiência como artista e diretor enriqueceu o novo processo, com o cuidado nas conduções poéticas e construções cênicas. Esse cuidado foi baseado na educação ancestral e afeto. Thiago Romero trouxe uma equipe para contribuir com a pesquisa cênica: Daniel Arcades, que refez o texto dramatúrgico do espetáculo, e Edeise Gomes que preparou os corpos para a cena, o movimento e a presença. A presença é para Pavis “o primeiro trabalho do ator, que não é trabalho propriamente dito, é o de estar presente, de se situar aqui e agora para o público, como um ser transmitido ao vivo sem intermediário" (PAVIS, 2011, p. 52). Estávamos presentes fisicamente e no nutrir de nossas memórias e histórias vividas na nossa solitude, ou aquilombados como uma grande família.

Fabíola Nansuré auxiliou na preparação corporal, com ênfase na dança dos orixás; a preparação vocal foi de Joanna Boccanera. Cabloco de Cobre e Heverton Didoné fizeram os experimentos musicais que ambientaram o espetáculo. Além disso, Cabloco de Cobre e Tamires Almeida foram responsáveis pela iluminação. Rafaela Tuxá cantou em algumas cenas e foi assistente de direção. Matheus Menezes e Luiz Antônio produziram o espetáculo. Sarai Reis confeccionou o figurino em parceria com o Teatro Castro Alves.

A preocupação do Coletivo era que os aspectos visuais (a iluminação, cenografia, maquiagem) valorizassem a negritude dos artistas, porque esses elementos materiais integram e dão sentido à cena. Com a complexidade da encenação, Interiores deixava de ser um experimento acadêmico para se engajar no circuito artístico.

Os direcionamentos da sala de ensaio aconteceram juntamente com a construção do texto e das cenas. Foram abordados diversos jogos teatrais e estímulos que foram experimentados no corpo como um laboratório propriamente dito. Os estímulos da força das palavras narradas formaram células cênicas, algumas foram aproveitadas ou aprimoradas com o novo texto dramatúrgico; outras foram abandonadas no processo. 
Cada artista convidado foi importante para o processo de encenação. Tínhamos um conjunto de narrativas e uma potência poética que ficavam evidentes pela formação do coletivo a partir dos laços entre afetos e aquilombamento (um terreno propício para criação de sentidos ontológicos e existenciais).

Numa sociedade em que prevalecem os imperativos das lógicas que primam pelos ditames do ter, pela hegemonia da produtividade e do consumo, da ordem do cálculo e da funcionalidade, mediante o regime dos processos hostis de exclusão, de competição e de indiferença, o Amor, em seus Sentidos primordiais, ontológico-existenciais é considerado uma heresia, uma experiência/vivência impertinente e prescindível. (ARAÚJO, 2016, p. 49)

Durante seis meses, os profissionais que conviveram e integraram com os artistas do Coletivo Fraude Pura se dedicaram de forma particular, partilharam suas experiências de ver o mundo e seus conhecimentos na construção cênica. Eles abordavam de forma especial a complexidade das narrativas e experiências dos artistas negros, suas características fenotípicas e signos linguísticos. Digo isso porque, no contexto das artes cênicas, comumente nos esbarramos com processos criativos que minimizam artistas afrodescendentes. São muitos estigmas e estereótipos que definem escolhas de personagens em função de papéis sociais limitados. Portanto, estar em processo de encenação que dá voz à luta antirracista é também uma forma de reafirmar o pertencimento étnico-racial e a identidade negra, algo que surgiu com o Teatro Experimental do Negro (TEN)

Com o TEN, criou-se uma tradição teatral brasileira que repensa e revisa as abordagens do corpo negro em cena. Nas construções cênicas, o papel de subalterno sempre era realizado pelo artista negro, sem desconstrução ou questionamento. Abdias Nascimento apontava a seguinte crítica:

A necessidade de organizações negras, dirigidas por negros, é um imperativo
que vem de nossa experiência histórica, e da plena consciência de que nossa
autodeterminação, o lugar que temos direito de ocupar em todos os níveis da
sociedade brasileira, depende unicamente de nós mesmos. (NASCIMENTO,
2019, p. 150)

Seguindo essa crítica, entendo que a formação do Coletivo Fraude Pura e seus processos de encenação demonstram a possibilidade de um aquilombamento teatral universitário como um espaço onde podemos nos organizar enquanto coletivo artístico; 
de construir nossa poética; e nos reconhecer para além dos estereótipos definidos na sociedade.

É no lugar de representação que tudo acontece. É onde se constrói o sentido que queremos dar às nossas montagens, e o que queremos abordar. É no processo de construção da cena que noções de pertencimento, memória individual e coletiva são elaboradas.

Ao pensar nesse corpo negro em cena e o uso dessas materialidades, vemos que “no teatro tudo é maquiado e mesmo 'montado': o rosto e o corpo têm sempre algo a esconder, como que para se vender melhor." (PAVIS, 2011, p.170). Na maioria das produções que têm pessoas negras em cenas, esses corpos não são valorizados. Nesses casos, eles já vêm repletos de signos linguísticos a serem analisados e repensados. No espetáculo Interiores, as materialidades foram pensadas para valorizar esses detalhes que ficam, na maioria das vezes, escondidos.

"A iluminação ocupa um lugar chave na representação, já que ela a faz existir visualmente, além de relacionar e colorir os elementos visuais (espaço, cenografia, figurino, ator, maquiagem), conferindo a eles uma certa atmosfera" (PAVIS, 2011, p. 179). O cenário era minimalista. O chão estava coberto por folhas secas. No alto, foram penduradas algumas cestas. A plateia estava próxima, e a música ao vivo dialogava com a memória dos integrantes. Os figurinos eram compostos de saias longas coloridas e uma camisa preta de manga longa. Os adereços eram colares de diversas cores, que se comunicavam com os cabelos armados das atrizes e atores. Tudo integrado com a iluminação em diálogo com os tons de peles negras, a dramaturgia e todo contexto cênico.

\section{Considerações finais}

A experiência junto ao Coletivo Fraude Pura me proporcionou trocas artísticas e pedagógicas dentro e fora da universidade. Com a transformação estética do modo de fazer teatro universitário nosso pensamento engajado na luta antirracista foi ampliado.

A pesquisa que realizei resultou em elaboração teórica e experimentação prática da cena junto ao aquilombamento-artístico-universitário, assim como suscitou uma pesquisa de conclusão do curso de Licenciatura em Teatro. O Coletivo Fraude Pura, por 
meio de sua poética, vivenciou o que podemos chamar de "afroafeto". Nele aprendemos que é possível, dentro de uma universidade pública, existir um engajamento político, cultural e social por meio de criações artísticas.

Formado por experiências de vida e auto narrativas dos autores-estudantes, o aquilombamento teatral universitário emerge da necessidade de reconhecimento de suas poéticas e de sua atuação enquanto sujeitos sociais. Para tanto, foi necessário revisitar as referências epistemológicas das artes cênicas e incluir referências negras.

Referenciar a presença do corpo negro em cena é descrever como o ator negro pode trazer, por meio de suas vivências pessoais, ferramentas e modos de criação artísticos com uma poética própria. O Coletivo Fraude Pura faz parte de uma família universitária que vê nas criações e nas discussões de determinados assuntos novos modos de ser e estar no mundo.

Sua poética faz com que possamos refletir os modos de se fazer o teatro negro universitário, baseado na estética negra, dialogando com as matrizes africanas e as narrativas de memórias. $\mathrm{O}$ espetáculo Interiores foi concebido a partir de um processo colaborativo que dialogou com as biografias em contexto ficcional. A partir de referências diversas, a criação dramatúrgica fundamentou-se nas memórias individuais dos atores e das atrizes, em diálogo com a cultura regional.

Finalmente, podemos considerar que o espetáculo Interiores foi um laboratório experimental realizado com o aquilombamento teatral universitário. Esse lugar de partilha de sentimentos, memórias e narrativas é um recorte para compreender o impacto da presença de artistas negros no contexto da formação artística universitária.

\section{Referências}

ALMEIDA, Silvio de. O que é racismo estrutural? Belo Horizonte: Grupo Editorial Letramento, 2018.

AKOTIRENE, Carla. Interseccionalidade. São Paulo: Sueli Carneiro; Polén, 2019.

ARAUJO, Miguel Almir Lima de. Dos sentidos do amor. Salvador: EDUFBA, 2016.

EVARISTO, Conceição. Tempo de nos aquilombar. Xapuri, 2020. Disponível em: xapuri.info/cultura/tempo-de-nos-aquilombar. Acesso em: 17 nov. 2020.

HOOKS, bell. Ensinando a transgredir: a educação como prática da liberdade. São Paulo: Editora WMF Martins Fontes, 2013. 
MARTINS, Leda Maria. Identidade e ruptura no teatro negro. Cadernos de linguística e teoria da literatura. Belo Horizonte, n. 18-20, 1987. Disponível em: http:// www.periodicos.letras.ufmg.br/indez.php/clt//issue/view/403. Acesso em: 28 nov. 2020.

MACHADO, Vanda. Pele da cor da noite. Salvador: EDUFBA, 2013.

NASCIMENTO, Abdias. O quilombismo: documentos de uma militância pan-africanista. São Paulo: Perspectiva, 2019.

PAVIS, Patrice. A análise dos espetáculos: teatro, mímica, dança, dança-teatro, cinema. São Paulo: Perspectiva, 2011.

RIBEIRO, Djamila. Lugar de fala. São Paulo: Sueli Carneiro; Polén, 2019.

SILVA, Jéssica Sampaio da. Aquilombamento-artístico-universitário: processo de afetos de interiores. 2020. Trabalho de Conclusão de Curso (Licenciatura em Teatro) - Universidade Federal da Bahia, Salvador, 2020.

SOARES, Stênio. As Poéticas da negritude e as encruzilhadas identitárias: uma abordagem a partir da noção de corpo-testemunha. Revista Rascunhos, Uberlândia, v. 7, n. 1, p. 10-29, 2020. Disponível em: seer.ufu.br/index.php/rascunhos/article/view/ 55518/292776. Acesso em: 18 jul. 2020.

SPINOZA, Benedictus de. Spinoza: obra completa IV: ética e compêndio de gramática da língua hebraica. São Paulo: Editora Perspectiva, 2014.

Recebido em: 09/08/2020.

Aceito em: 18/03/2021. 